transplantation on adolescents' self-identity development. This presentation will discuss the struggles that adolescent transplant recipients experience as they endeavour to incorporate a new kidney into their embodied self. These findings were identified as a predominant theme from a narrative inquiry of embodiment experiences among young people living with CKD in Ireland.

Methods This study employed a narrative inquiry research design. Using an ethnographic approach data were gathered through multi-media approaches including: visual body maps (i.e. life-size human body images), oral informal conversations and observational field notes. Five adolescents (10-17 years) participated in the study, which took place over a period of 18 months as adolescents experienced living with CKD in both hospital and home settings.

Results A nuanced finding identified from this study was a disrupted sense of self and identity arising from adolescents' encounters with a foreign body part (i.e. kidney). Adolescent participants experienced a tension between their body, self and identity as a consequence of transplant surgery. They struggled to adjust to the presence of a foreign organ from a deceased donor and they were concerned about developing personality characteristics of the donor As one participant described, the kidney was not viewed as her own but was conceptualized as 'a dead persons kidney'. Another participant described the prospective of acquiring the personal qualities or characteristics of the donor as 'disgusting'. Findings also revealed that adolescents engaged in different individualised ways to cope with the transplanted organ.

Discussion The findings from this study provide an understanding of the struggles adolescents endure as they attempt to incorporate a foreign organ within their bodies and the potential impact on their self-identity. Clinicians need to be aware that substituting kidneys with donor organs is much more than a complex technical procedure; it requires an amalgamation of 'other' and 'self'. From a clinical perspective, a multifaceted and holistic person-centred care approach is needed to equip adolescents with the individual skills required to adapt to a new kidney.

\section{OC11 CURRENT BREAST FEEDING PRACTICES AND FACTORS AFFECTING ITIN AL-BAHA REGION, SAUDI ARABIA(PRE \& POST - INTERVENTION)}

1,2,3Mahmoud Rashad Salwa Rashad* ${ }^{1}$ Carmen Nassar, ${ }^{4}$ Salwa Rashad. ${ }^{1}$ King Fahd Hospital, Al Baha, Saudi Arabia; ${ }^{2}$ Al Azher University, Cairo, Egypt; ${ }^{3}$ Egyptian Society of Breast Milk Friends, Cairo, Egypt; ${ }^{4}$ Wisconsin University, Madison, USA

10.1136/archdischild-2019-epa.11

Introduction and aim of the work Breast feeding (B.F.) is now considered a basic human right for every newborn infant, as well as of his/her mother. The WHO and UNICEF have emphasized the importance of promoting B.F. as a way to improve the health and nutrition of infants and young children.

The objective of this study was to find out the prevalence of B.F., the social, demographic and medical influencing factors related to the initiation and continuation of B.F., the knowledge and attitude of females towards B.F. in Al-Baha, Saudi Arabia. Also, to determine the weak points and common misbeliefs, which should be considered during the intervention stage.
Subjects and methods The study was conducted in Al-Baha region, Saudi Arabia (twice) in the period between January and November, 2015 (pre-intervention) and 2016 (post-intervention). Pre-intervention study was followed by intervention plan in form of workshops for physicians and mothers, and establishment of breast feeding clinic in $\mathrm{KFH}$ and use of educational materials in $\mathrm{Al}$ Baha hospitals. In both studies, participants were 714 mothers having 714 infants below 24 months, from both sexes and equally distributed among six age groups. All the sampled mothers completed answering questionnaires.

The results The results showed remarkable improvement in all breastfeeding rates, but still far below international safe rates. Post- intervention versus pre-intervention results showed: significantly less percent of mothers who never breast feed, increase $\geq 4$ times in the percent of mothers who had BFD= $(30-120)$ and $\mathrm{BFD}=(120-240)$ and similar percent of mothers who had BFD higher than 240 days. Regarding education of the mothers, there was significant increase in $\mathrm{BF}$ rate specially in mothers who cannot read or write and those whose education level is before high school. Also the increase in $\mathrm{BF}$ rate was more in working mothers (3times) and in mothers from families with high income than non working ones and those from low income families respectively. The factors most significantly associated with the outcome of breast feeding were the early supplements, misperceptions, mother's education, working mothers, baby refusal, contraceptives, inconvenience and use of teats. The mother's knowledge about BF was very poor in both studies but improved in post-intervention study.

Conclusion The current study emphasizes that the most significant factors affecting the outcome of breast feeding are highly modifiable by health education. This information is crucial for the development of a successful breastfeeding promotion plan in this community.

\section{OC12 ASSOCIATION BETWEEN DEPRESSION AND CARDIOMETABOLIC RISK FACTORS IN OVERWEIGHT AND OBESE TURKISH ADOLESCENTS}

${ }^{1}$ Aslı Okbay Güneş*, ${ }^{2}$ Müjgan Alikaşifoğlu, ${ }^{3}$ Ethem Erginöz, ${ }^{4}$ Rahime Hülya Bingöl, ${ }^{4}$ Ezgi Şen Demirdöğen, ${ }^{4}$ Türkay Demir, ${ }^{5}$ Selmin Köse, ${ }^{1}$ Emre Çelik, ${ }^{6}$ Oya Ercan. ${ }^{1} /$ stanbul University- Cerrahpaşa, Department of Pediatrics, istanbul, Turkey; ${ }^{2}$ Istanbul UniversityCerrahpașa, Department of Pediatrics, Division of Adolescent Medicine, istanbul, Turkey; ${ }^{3}$ Istanbul University- Cerrahpaşa, Department of Public Health, Istanbul, Turkey; ${ }^{4}$ stanbul University-Cerrahpaşa, Department of Child and Adolescent Mental Health and Diseases, istanbul, Turkey; ${ }^{5}$ Istanbul Bilim University, School of Health, istanbul, Turkey; ${ }^{6}$ Istanbul University-Cerrahpaşa, Department of Pediatrics, Division of Adolescent Medicine and Endocrinology, ìstanbul, Turkey

\subsection{6/archdischild-2019-epa.12}

Objective The aim of this study was to determine the prevalence of depression in obese and overweigth adolescents and, to evaluate the relationships between depression and cardiomethabolic risk factors in obese and overweight adolescents.

Method We performed a retrospective cross-sectional analysis of the data from overweight or obese adolescents 11 to 18 years of age who were evaluated in our clinic from January 2012 to December 2015. Depression was evaluated by Children's Depression Inventory. Hypertension, dyslipidemia, hyperinsulinemia, hyperglycaemia and insulin resistance were defined as cardiometabolic risk factors. For statistical analysis, Chi-square test and logistic regression analysis were used. 